\title{
Sobre a Pesquisa de História ANTiga no Brasil
}

O texto apresentado pelos autores Dominique Santos, Graziele Kolv e Juliano João Nazário tem vários méritos. O principal deles, em minha opinião, é a proposta de sistematização de informações relacionadas ao campo da História Antiga no Brasil a partir de um referencial que perpassa quase a totalidade dos pesquisadores brasileiros situados em universidades públicas e algumas particulares onde a área de História Antiga é preenchida por um especialista: a necessidade de organização de dados de sua carreira em forma de currículo abrigado na Plataforma Lattes. Além disso, a própria metodologia de análise desse tipo de currículo é apresentada de forma explícita, o que permite ao leitor/interlocutor pensar sobre os critérios dos autores. Ou seja, trata-se de uma análise caracterizada como "sistemática", mas não total, e os elementos que estão na base das escolhas parecem bem definidos.

Trata-se de um primeiro passo fundamental para o mapeamento de temas pesquisados, concentrações regionais, orientações etc., em época de justificação da manutenção de temas relacionados à História Antiga que vem sendo apresentada em amplos debates nacionais sobre o currículo de História, e debates mais amplos repensando o lugar da História Antiga em narrativas da história da civilização ocidental, redefinindo-se fronteiras e os lugares dos historiadores que se engajam nesses debates. Assim, o pesquisador brasileiro, geralmente situado na periferia da história, da disciplina e desse processo histórico, passa a refletir sobre o seu lugar em um contexto de crise. Ou seja, pensar o campo a partir de dados objetivos é uma ação das mais importantes para que as reflexões propostas nos debates vindouros não sejam fruto de puro preconceito ou apenas intuitivas. Dessa forma, iniciativas como a dos autores do texto são muito bem-vindas.

No texto, há muitas questões que poderiam ser discutidas pormenorizadamente; entretanto, escolhi algumas que identifiquei como mais relevantes considerando a proposta do artigo: uma reflexão sobre a pesquisa de História Antiga no Brasil. Excluo, conscientemente, o ensino e a explicação para

\footnotetext{
${ }^{1}$ Professor Adjunto da EFLCH-UNIFESP, área de História Antiga.
} 
isso será apresentada ao longo deste comentário. Assim, para o estabelecimento de um diálogo com o texto aqui comentado, proponho a reflexão de três pontos: a questão do professor/pesquisador de História Antiga no Brasil; a pequena representatividade dos estudos sobre as sociedades orientais antigas; e o percurso formativo dos pesquisadores em questão. Comentarei também, ao longo deste texto, a adequação da fonte documental e do método de análise escolhidos pelos autores.

\section{Ensino e pesquisa de História Antiga no Brasil?}

Inicialmente, é interessante pensar no título do texto "O ensino e a pesquisa de História Antiga no Brasil: reflexões a partir dos dados da Plataforma Lattes", que me parece parcialmente equivocado. Trata-se, a meu ver, de um texto que apresenta alguns elementos relacionados, sobretudo, à formação e projetos de pesquisadores da área de História Antiga no Brasil, e não propriamente da questão do ensino dessa disciplina. O início do artigo trata de uma perspectiva mais ampla no que se refere ao ensino de História Antiga no Brasil, incluindo alguns eventos considerados importantes como a presença da disciplina em escolas de Ensino Médio já no século XIX, é o caso do Colégio Pedro II; mas o texto trata especialmente de profissionais que atuam nos domínios da pesquisa acadêmica, universitária. E, nesse caso, mesmo o âmbito do ensino em meio universitário não é discutido mais precisamente no texto.

No Brasil, e em muitos outros países, é clara a forte aproximação entre pesquisa universitária e ensino. Há, mesmo, debates em curso entre a formação de pesquisadores e as estratégias de ensino universitário, e a própria situação do pesquisador-docente em importantes centros brasileiros de pesquisa. Esses debates acontecem em torno de uma questão básica: a atividade de pesquisa financiada pelo poder público no Brasil é relacionada, em sua grande maioria, à universidade, tendo sido desenvolvida, ao longo do tempo, uma íntima relação entre ensino e pesquisa, o que justificaria a proposta presente no título do texto aqui comentado. A situação é diferente em países como a França, que também possui pesquisadores-docentes em várias universidades, mas em que há centros exclusivos de pesquisa, como o CNRS (Centre National de la Recherche Scientifique), onde a atividade de docência não é prevista. 
Entretanto, no Brasil, mesmo com essa configuração que aproxima consistentemente as atividades de pesquisa e docência, o ensino de História, mais especificamente o ensino de História Antiga, não se explica exclusivamente nos termos dessa aproximação. $\mathrm{O}$ ensino como tema mereceria uma abordagem mais delimitada considerando sua especificidade como campo do conhecimento teórico e aplicado. Ou seja, o ensino, no texto aqui comentado, aparece de forma indireta, como uma atividade relacionada à pesquisa. $\mathrm{O}$ que quero dizer é que a compreensão de aspectos da formação e da pesquisa de docentes é insuficiente para se pensar o ensino como fenômeno social, mesmo quando ele está intimamente ligado à pesquisa. Dessa forma, sua relação com a pesquisa acadêmica deveria ser mais detidamente discutida.

As tabelas apresentadas no texto aqui comentado, uma síntese do esforço de análise quantitativa, indicam um pouco dessa apresentação indireta do fenômeno do ensino de História Antiga no Brasil. Por exemplo, a primeira delas, "Docentes de História Antiga por Região", não é discutida a partir da problemática da presença/ausência de docentes e suas consequências em cada região do Brasil, mas uma identificação de certas concentrações por regiões. Mais que isso, o título poderia ser modificado para "Pesquisadores de História Antiga por Região" sem qualquer prejuízo. Todas as outras tabelas ("Conhecimento de Idiomas", "Países visitados", "Países visitados para Doutorado Pleno", "Países visitados para Doutorado Sanduíche", "Países Visitados para Estágio de Pósdoutoramento", "Pesquisadores por área de interesse", "No de Trabalhos de Conclusão de Curso de Graduação", "No de Trabalhos de Conclusão de Curso de Especialização", "Número de Dissertações produzidas" e "Número de Teses produzidas") são mais ligadas à lógica da formação do pesquisador.

Considerando essa questão e a fonte que os autores utilizaram, ou seja, os currículos dos pesquisadores de História Antiga em universidades brasileiras sediadas na Plataforma Lattes, é interessante notar que a reflexão sobre a formação, pesquisa e orientações dos especialistas observados por meio de seus currículos não indica com clareza os conteúdos que são apresentados em seus cursos universitários por exemplo. Se, por outro lado, considerarmos as orientações em curso e concluídas, o problema da formação do pesquisador e, indiretamente, do ensino, parece oferecer um nível mais bem definido para este debate. Ou seja, parece que é apenas no campo da formação especializada 
(iniciação científica, trabalhos de conclusão de curso, mestrados e doutorados), que a questão de ensino e pesquisa é satisfeita pela análise do currículo Lattes. Entretanto, considerando a abrangência do ensino de História Antiga, cobrindo níveis desde a formação escolar básica até a pós-graduação em universidades, a análise dos currículos dos pesquisadores não parece satisfazer uma reflexão suficientemente abrangente do ensino de História Antiga.

Além disso, em âmbito acadêmico (o nível de análise proposto), não são discutidos elementos fundamentais como abordagens metodológicas em ensino de História Antiga, os temas tratados, grades curriculares, a interação entre pesquisa e ensino e as relações entre o conhecimento produzido na universidade e aquele próprio da formação escolar nos ensinos Fundamental e Médio. Esses são temas que, muito provavelmente, não são claramente observáveis no currículo Lattes. Talvez por isso, esse tipo de fonte não seja adequado para se pensar, de forma mais detida, questões relacionadas ao ensino em uma abordagem quantitativa. $O$ currículo Lattes cumpre um papel acadêmico, voltado ao universo da pesquisa, e parece que a natureza da fonte que os autores do texto aqui comentado escolheram interfere fortemente na questão colocada e no seu alcance interpretativo. A sensação que fica é que o texto apresenta a formação e temas de pesquisa daqueles que ensinam História Antiga, mas não o que e como ensinam.

Se, com isso, trata-se de um texto mais detidamente organizado em torno da compreensão da formação dos pesquisadores de História Antiga no Brasil, com delimitações cronológicas organizadas em torno da própria existência desse tipo de informação à disposição, suas pesquisas e orientações indicadas no Currículo Lattes, o texto poderia distinguir, no panorama histórico que precede a análise quantitativa dos currículos, elementos como a tradição clássica no Brasil, ensino de História Antiga e a pesquisa de História Antiga que aparecem com certo grau de equivalência. Considero importante notar que o ensino de línguas clássicas já era presente nesta região que depois seria organizada como o estado nacional brasileiro desde o período colonial como os autores indicam; entretanto, quais são as conexões entre essa presença da "tradição clássica", a instauração da universidade no Brasil e a criação de disciplinas de História Antiga? Não seria interessante pensar em uma problematização histórica que contemplasse o contexto discutido, a formação dos profissionais que atuam em universidades 
brasileiras e a existência da ferramenta que organiza as informações relacionadas aos seus currículos? Assim, em vez de uma inserção da História Antiga em uma narrativa sobre a tradição clássica no Brasil, uma contextualização que contemplasse mais profundamente o campo de pesquisa, seus agentes e a fonte documental que os autores do texto aqui comentado utilizaram seria também bem-vinda.

\section{O lugar do estudo das "sociedades orientais" antigas}

Pensando nos "Estudos Clássicos" e sua relação com a História Antiga, algumas questões importantes podem ser destacadas. Por exemplo, o lugar do que os autores chamam de "sociedades orientais" antigas na História Antiga brasileira, o que é discutido no texto; e a formação dos pesquisadores em um ambiente "interdisciplinar", próprio dos Estudos Clássicos, como a forte relação entre História Antiga e Arqueologia Clássica (ou, como atualmente vem sendo chamada, Arqueologia do Mediterrâneo Antigo), o que não foi discutido no texto.

Quanto ao primeiro ponto, a partir da análise quantitativa, os autores do texto aqui comentado identificam uma pequena parcela de pesquisadores voltados aos estudos das sociedades orientais antigas, caracterizando a História Antiga no Brasil como pouco diversificada, e conclamando esforços para a continuidade do trabalho dos professores Ciro Flamarion Cardoso e Emanuel Bouzon. Dois elementos importantes podem ser pensados sobre isso. O primeiro é a negação de diversificação das pesquisas de História Antiga no Brasil. Ora, é devido identificar que esse campo citado é pouco representativo do ponto de vista quantitativo na composição do amplo grupo de pesquisadores de História Antiga no Brasil, o que merece um profundo debate. Entretanto, isso não significa que a História Antiga no Brasil não seja diversificada. Os rótulos "Grécia" e "Roma" presentes nos currículos no item "área de interesse" provavelmente escondem um repertório enorme de recortes específicos: territoriais, de abordagem, de orientação teórica, da natureza da fonte etc.

Ao contrário dos autores do texto, considero que a História Antiga no Brasil seja composta por pesquisadores de orientações bastante diversificadas, mesmo identificando clara deficiência (do ponto de vista quantitativo) na composição de certos itens como os estudos das sociedades orientais antigas. Ou seja, a pouca diversificação notada pelos autores é correspondente a um aspecto 
detido da História Antiga - seus componentes de base cronológico-culturais. Entretanto, mesmo os rótulos "Grécia" e "Roma" escondem outras importantes ausências internamente. Por exemplo, no Brasil, há pouquíssimos pesquisadores voltados para o estudo da Idade do Bronze no Egeu.

O segundo ponto é a própria necessidade de ampliação dos estudos sobre as sociedades orientais antigas. No texto, há varias possíveis explicações para o fenômeno da pequena representatividade dessa área no Brasil. Nenhuma delas aventa, por exemplo, a íntima relação entre pesquisadores brasileiros de História Antiga e as academias europeias. A análise quantitativa apresentada pelos autores do texto aqui comentado indica um forte direcionamento desses profissionais a países como a França e a Inglaterra, onde suas academias organizaram tais campos de conhecimento e os estruturaram em torno de questões científicas e também ideológicas. Intuitivamente, é possível notar que a representatividade dos "orientalistas" pesquisadores dessas sociedades antigas também aparece em menor quantidade na Europa. Ou seja, será que o interesse mais concentrado por temas como "Grécia" e "Roma" não está conectado à manutenção dessa forma de organização europeia do conhecimento sobre o Mundo Antigo na pesquisa sobre a História Antiga no Brasil? Será que a nossa formação, ainda fortemente ligada a academias europeias, não influencia essa composição desequilibrada aqui no Brasil?

A resposta não é certa, mas há linhas de pensamento importantes a partir dessa questão. Uma delas é: porque temos que continuar estudando as sociedades orientais antigas? E quais delas deveríamos estudar? Particularmente, considero de fundamental importância tais estudos. Entretanto, é preciso notar que a composição da História Antiga em áreas como Antigo Oriente Próximo, Egito, Grécia e Roma antigos tem como base um projeto narrativo civilizatório, muitos diriam, imperialista. Um exemplo disso é a tradicional inserção do "Oriente" apenas em momentos específicos dessa ampla narrativa, como a transição do Neolítico para a Idade do Bronze, o que aparece ainda em várias publicações como "origem da história", "origem da civilização", "revolução urbana" etc.; e, depois, em interações com as sociedades "clássicas" como algumas cidades gregas no norte da África, a lógica do comércio oriental do Mediterrâneo, algumas províncias romanas, entre outros. Assim, qual "Oriente" antigo devemos estudar? Aquele da Idade do Bronze e que estabeleceu relações com o "mundo clássico"? A 
verdadeira questão é: estudar tais sociedades orientais, Grécia e Roma significa ainda recuperar parte do percurso narrativo da história da civilização ocidental? Ou seja, a conclamação dos pesquisadores brasileiros a preencherem lacunas deveria ser precedida de uma discussão sobre a própria natureza da lacuna, e se estamos dispostos a reconhecê-la como uma deficiência.

Outro problema relacionado é a ampla identificação entre a História Antiga e os Estudos Clássicos. Por mais que essa área não tenha se desenvolvido de forma mais profunda no Brasil, como centros de pesquisas integradas propondo efetivas interações entre profissionais que se dedicam a temas da História, Arqueologia, Estudos Literários e Filosofia das chamadas sociedades clássicas, há instituições importantes que congregam tais profissionais, como a SBEC (Sociedade Brasileira de Estudos Clássicos). A própria narrativa que os autores do texto aqui comentado apresentam transita mais consistentemente entre História Antiga, tradição clássica e Estudos Clássicos. Ora, entre narrativas, instituições e propostas de diálogos estruturados em torno do "clássico", qual o papel do "Oriente" Antigo e da "Grécia" da Idade do Bronze já que ambos são excluídos do "mundo clássico"? O fortalecimento dessa perspectiva tendo o clássico como referencial não seria excludente? Essas questões mostram que a História Antiga, colocada em perspectiva, situa-se diante de um cenário de opções críticas. Penso que é nesse contexto que a questão do "Oriente Antigo" poderia ser pensada.

\section{A formação dos pesquisadores: a História Antiga e os Estudos Clássicos}

Na outra extremidade da questão, mas ainda tratando das interações possíveis da História Antiga no âmbito dos Estudos Clássicos, é importantíssimo pensar no percurso formativo dos pesquisadores de História Antiga no Brasil. Os autores do texto aqui comentado preferiram lidar com os temas das pesquisas, $o$ que também é importante, mas não com as disciplinas que estão na base da formação desses pesquisadores. É importante notar que muitos deles não são pós-graduados em História, o que revela contornos mais diversificados em sua formação. Um exemplo claro são as relações entre História Antiga e Arqueologia Clássica no Brasil. Esse diálogo é bastante comum em centros de Estudos Clássicos bem desenvolvidos na Europa e nos EUA, considerando o interesse de historiadores pelas fontes materiais e a característica interdisciplinar da 
Arqueologia, que dialoga frequentemente com a História, História da Arte, Estudos Literários etc.

No Brasil, não é possível pensar no desenvolvimento da História Antiga sem considerar esse forte diálogo com a Arqueologia Clássica no tocante à formação de profissionais. No que se refere aos estudos de Grécia Antiga, por exemplo, o arqueólogo Ulpiano Toledo Bezerra de Meneses, que se formou em Letras Clássicas, tornou-se professor de História Antiga da Universidade de São Paulo, orientando poucas pesquisas na área, mas é ainda uma importante referência para os estudos de cultura material. A arqueóloga Haiganuch Sarian, que também se formou em Letras Clássicas, transitou entre o Departamento de Antropologia e o Museu de Arqueologia e Etnologia da Universidade de São Paulo, orientou vários pesquisadores que, com diplomas de pós-graduação em Antropologia ou Arqueologia, são professores de História Antiga no Brasil.

Assim, pesquisadores pós-graduados como arqueólogos/antropólogos, mas atuando em departamentos de História, formaram um expressivo grupo de historiadores que atualmente são pesquisadores em universidades públicas brasileiras. São os casos, por exemplo, de Norberto L. Guarinello (USP) e Pedro P. A. Funari (UNICAMP). Mesmo a professora Sarian continua a orientar e muitos de seus ex-orientandos, como o autor deste texto, lecionam em departamentos de História como professores de História Antiga. Dessa forma, a contribuição da Arqueologia Clássica foi importante para o desenvolvimento da História Antiga no Brasil. Pode-se, mesmo, dizer que, enquanto a Arqueologia Clássica contribuiu significativamente para a estruturação da História Antiga no Brasil, esqueceu-se de se fortalecer como disciplina. Nesse sentido, há pouquíssimas vagas específicas para esse tipo de arqueólogo em instituições acadêmicas brasileiras, e o arqueólogo é, muito frequentemente, integrado aos cursos de história como docente.

Trata-se, nesse caso, de um fenômeno de organização de duas disciplinas próximas no Brasil, o que não chega a ser explorado pelos autores do texto aqui comentado. Nesse tipo de análise, a formação dos pesquisadores é um elemento fundamental, e as informações para quantificá-la estão disponíveis nos currículos, o que não foi observado. Dessa forma, contribuições como essa, organizadas em torno do diálogo entre História Antiga e Arqueologia Clássica, que ainda atualmente influenciam a composição do campo, não chegaram a ser 
ao menos citadas. Mais que isso, é possível observar na formação desses profissionais, um universo variado quase composto em torno dos Estudos Clássicos: falou-se, aqui, em profissionais que transitaram entre a formação em Letras, Arqueologia e História. Não seria importante observar o cenário amplo para que se possa compreender também o percurso formativo dos pesquisadores de História Antiga no Brasil?

Na minha percepção, mais que uma leitura sociológica do campo da História Antiga no Brasil, o texto aqui comentado é uma primeira proposta de observação de um quadro básico de dados, cuja análise é centrada em alguns contornos quantitativos de elementos que os autores consideraram significativos para a compreensão desse campo. Contudo, parece que tais escolhas não foram exclusivamente centradas no que o currículo apresenta, mas também em uma perspectiva de compreensão da História Antiga no Brasil. Como visto, a Arqueologia como uma forte contribuidora para a História Antiga não apareceu como dado efetivo, já que a formação do pesquisador (área que cursou na graduação e pós-graduação) não foi observada. Considero que seja um dado importante. Outros tantos também são, como a composição da área por gênero. Por mais que esse debate seja extremamente complexo, não redutível à lógica binária homem/mulher, esse é um tipo de informação que poderia ser aproveitada, considerando que esse elemento possa interferir no campo da História Antiga no Brasil.

Há, ainda, a cronologia da formação (a trajetória de um pesquisador em História Antiga no Brasil antes de se tornar docente dura quanto tempo em média? E o seu tempo de docência/pesquisa?), a consistência dos vínculos entre os pesquisadores e as universidades em que atuam (passam muito tempo em uma universidade? Mudam de uma para outra frequentemente?), quais agências de fomento mais financiam os projetos? Qual é o quadro proporcional de investimentos em pesquisas por região? Além disso, é importante pensar no cruzamento desses dados. E, ainda sobre a formação dos pesquisadores, a proporção entre aqueles que possuem licenciatura e (ou) bacharelado poderia ser também quantificada, sobretudo quando a questão aparece discutida nas considerações finais do texto. Todos esses elementos podem ser observados a partir do currículo dos pesquisadores na Plataforma Lattes, e tais ausências 
interferem severamente na proposta que se apresenta como uma análise sistemática da produção dos pesquisadores de História Antiga no Brasil como um diagnóstico do campo. Dessa forma, seria interessante refletir um pouco mais sobre a qualidade das informações disponíveis no currículo Lattes e quais informações ali apresentadas poderiam contribuir para uma compreensão mais profunda da pesquisa de História Antiga no Brasil, mesmo que em uma proposta inicial organizada a partir de quantificações mais simples e o cruzamento de dados.

Por fim, proponho refletirmos se os dados apresentados não indicariam, em vários casos, opções firmadas pelos pesquisadores brasileiros de História Antiga. Por exemplo, os fortes diálogos com a Europa e uma frágil articulação latino-americana podem revelar mais que a busca de centros de excelência em pesquisa sobre a Antiguidade, mas também a manifestação da manutenção de elementos da proposta europeia na pesquisa que se desenvolve no Brasil. A pequena representatividade de pesquisadores que se dedicam às sociedades orientais antigas não revelaria certa rejeição desse campo em face de uma identificação crescente entre História Antiga com os Estudos Clássicos? Enfim, esses dados apresentados no texto aqui comentado colocam-nos diante de um espelho. Resta saber se vamos encarar a imagem refletida como uma pintura a óleo emoldurada, fixa, ou um instantâneo fotográfico que nos indica a efemeridade de um momento presente e, por isso, enseja reflexões para o futuro. 